\title{
CONF-9503196--1
}

UCRL-JC-119642

PREPRINT

\section{Two Wavelength Division Multiplexing WAN Trials}

W. J. Lennon

R. L. Thombley

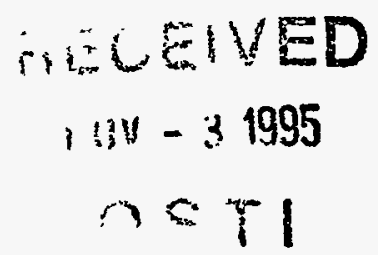

SHLENED

I) 31995

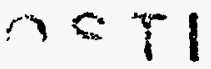

This paper was prepared for submittal to the

IEEE Compcon 95

San Francisco, CA

March 5-9, 1995

January 20, 1995

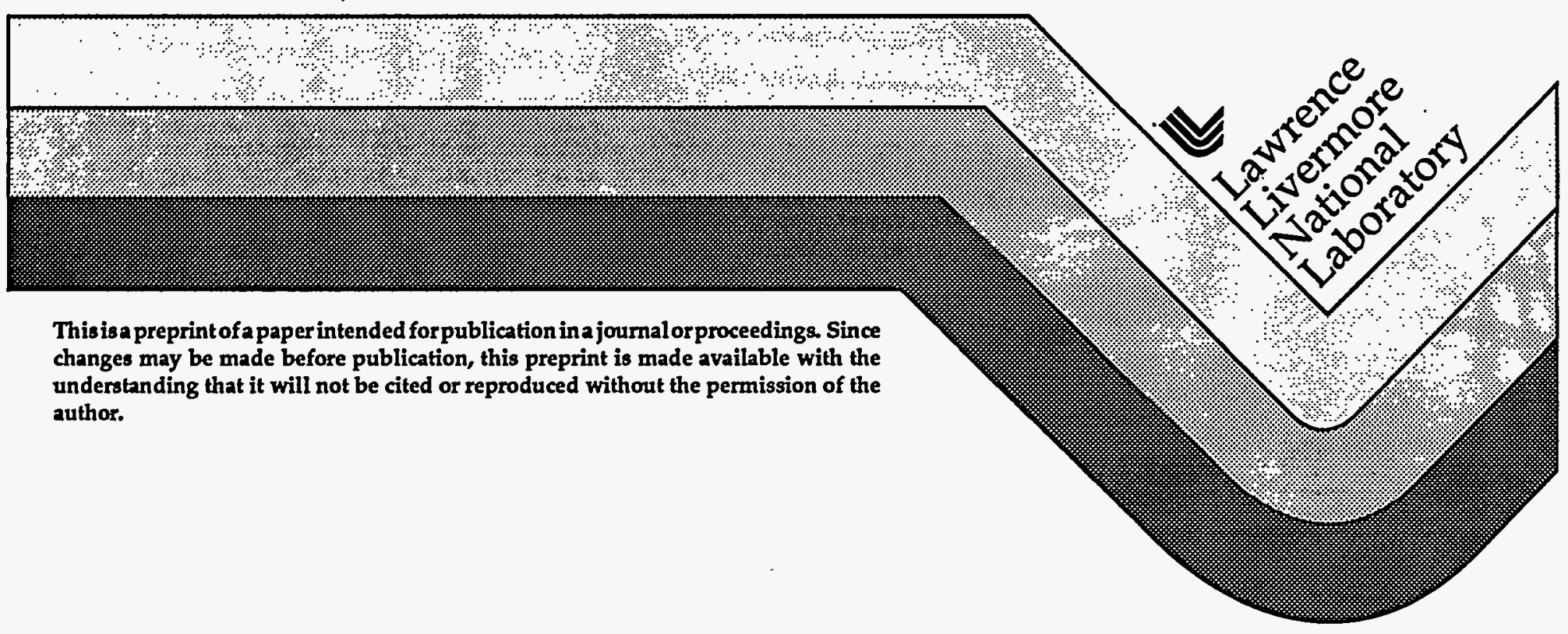

This is a preprint of a paper intended forpublication in a journal orproceedings. Since changes may be made before publication, this preprint is made available with the understanding that it will not be cited or reproduced without the permission of the author.

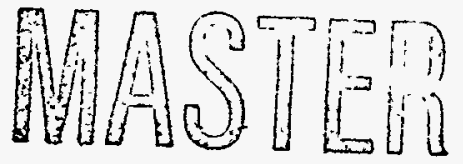




\section{DISCLAIMER}

This document was prepared as an account of work sponsored by an agency of the United States Government. Neither the United States Government nor the University of California nor any of their employees, makes any warranty, express or implied, or assumes any legal liability or responsibility for the accuracy, completeness, or usefulness of any information, apparatus, product, or process disclosed, or represents that its use would not infringe privately owned rights. Reference herein to any specific commercial product, process, or service by trade name, trademark, manufacturer, or otherwise, does not necessarily constitute or imply its endorsement, recommendation, or favoring by the United States Government or the University of California. The views and opinions of authors expressed herein do not necessarily state or reflect those of the United States Government or the University of California, and shall not be used for advertising or product endorsement purposes. 


\title{
Two Wavelength Division Multiplexing WAN Trials
}

\author{
W. J. Lennon \\ R. L. Thombley \\ Lawrence Livermore National Laboratory \\ 7000 East Avenue, L-557, Livermore, California 94551-0808
}

\begin{abstract}
Lawrence Livermore National Laboratory, as a super-user, supercomputer, and super-application site, is anticipating the future bandwidth and protocol requirements necessary to connect to other such sites as well as to connect to remote-sited control centers and experiments. In this paper we discuss our vision of the future of Wide Area Networking, describe the plans for a wavelength division multiplexed link connecting Livermore with the University of California at Berkeley and describe plans for a transparent, $\approx 10 \mathrm{~Gb} / \mathrm{s}$ ring around San Francisco Bay.
\end{abstract}

Keywords: fiber communication links, wavelength division multiplexing, WDM, Fibre Channel, Wide Area Networks, WAN.

\section{1: LLNL telecommunications}

\section{1: Environment}

Lawrence Livermore National Laboratory (LLNL), managed by the University of California for the U. S. Department of Energy, has achieved 40 years of excellence in creating and applying science and technology to meet vital national security needs. LLNL is a major national resource whose mission areas have been expanded by the federal government to address a broad spectrum of evolving national needs, including national security, energy, the environment, health and biomedicine, information and communication sciences, economic competitiveness, and science and math education.

Users advancing LLNL's mission objectives have always demanded exceptional computer, network and mass storage support. As a result the Laboratory has tended to install new infrastructure technology three to five years before private industry. In addition to having an extremely large on-site production network and one of the largest ISDN (digital) telephone systems 'in captivity,' LLNL manages the DOE's portion of the Internet.

\section{2: Advanced Telecommunications Program}

The mission of LLNL's Advanced Telecommunications Program is to anticipate the Laboratory's future telecommunications needs, test alternatives and spawn migration efforts to install those that work. The program has thrce goals: to eliminate on-campus network bottlenecks which prevent users' reaching their full creative potential, to extend that connectivity between Livermore and off-site peer collaborators and resources, and, to foster technology which will make the National Information Infrastructure more affordable. Our projects in these threc areas are driven by both laboratory and national needs. Our three project areas complement and leverage each other's results. All projects involve active collaboration with private industry, other national or govemment laboratories, and universities.

'Delivering a billion bits a second to every work site' characterizcs the goal of projects which address on-campus network bottlenecks. By picking a figure of merit which corresponds to the bandwidth of the optic nerve, we aim bcyond current incremental improvements and hope to deploy an infrastructure requiring few future changes.

We have collaborated with private industry to make Fibre Channel a viable ANSI standard. For example, we have established a joint LLNL/industry Fibre Channel interoperability test bed to foster pre-competitive cooperation in defining a large enough marketplace in which vendors can subsequently compete.

The majority of our ATM activities have centered about our joining or helping to found experimental and prototype Gigabit [per second] Wide Area Networks (WAN's) for pioncer high performance applications traffic. We are partncrs in the 'longest' and 'densest' such WANs. AT\&T's cXpcrimental University NETwork (XUNET) hosts BLANCA, a national $\mathrm{Gb} / \mathrm{s}$ network that links Bell 
Laboratories and Livermore with intermediate sites at Rutgers, University of Illinois, University of Wisconsin, UC Berkeley, Lawrence Berkeley Laboratory and Sandia National Laboratory at $45 \mathrm{Mb} / \mathrm{s}$ cross country with 622 $\mathrm{Mb} / \mathrm{s}$ links in the midwest. We have added a $622 \mathrm{Mb} / \mathrm{s}$ link between LLNL and UC Berkeley. The Bay Area Gigabit Network (BAGNET) links 15 high tech firms in the San Francisco Bay Area at $155 \mathrm{Mb} / \mathrm{s}$ data rates. Plans are being discussed to upgrade some of its links to 622 $\mathrm{Mb} / \mathrm{s}$. These are the maximum rates likely to be available to individual users for several years. However, equipment is routinely deployed to aggregate this and lower speed traffic onto $2.5 \mathrm{~Gb} / \mathrm{s}$ capacity 'backbones.'

Our efforts to make the fiber infrastructure more affordable are currently centered upon advancing the deployment of wavelength division multiplexing (WDM). We have three projects in this area. First is a collaboration with Pacific Bell to test the fielding of fiber amplifiers and WDM which will be described in the rest of this paper. The second is a consortium to examine a particular 'all optical network' architecture and develop enabling electrooptic components. The third project will build upon the products and experience of the collaborators on the first two by using Pacific Bell and Sprint fiber resources to deploy a transparent optical network that rings San Francisco Bay with a 10 to $80 \mathrm{~Gb} / \mathrm{s}$ aggregate data capacity.

\section{2: An affordable 'information superhighway'}

The 'information superhighway' vision assumes every citizen in the nation will have easy, affordable access to the information and the economic and educational advantages that such a global inter-network will provide. Though we have made this vision a national priority there are still technical problems that stand in the way of creating a network that is fast enough and inexpensive enough to qualify as the 'superhighway.' The cost effective expansion of the existing infrastructure to mect even modest telecommunications demand growth will require an increase in the capacity and the flexibility of the installed national fiber base.

\section{1: Capacity}

We must increase the capacity of each installed fibcr in the infrastructure. Replicating traditional network elements to increase capacity will be prohibitively expensive. It would require digging new trenches, pulling, terminating and connecting new fiber cables. The additional connectors alone would cost billions of dollars.

The majority of today's long distance fibers combine low specd voice, video and data traffic into a $2.5 \mathrm{~Gb} / \mathrm{s}$ data channcl using a single wavelength. Modest growth demand for such uses will quickly yield data volumes which exceed the capacity of fibers using similar, but faster, $10 \mathrm{~Gb} / \mathrm{s}$ data channels.

Even greater growth demand will take place if - predictions of new applications in entertainment, medical image or financial transaction imaging are sound. And just beyond the turn of the century, we can expect the long predicted paradigm shift to occur-when telephones become video phones.

In order to deliver substantially faster data rate channels, industry must develop and master the volume production techniques for electro-optic components with much smaller feature sizes. The maximum, cost effective data rate per wavelength will probably be $10 \mathrm{~Gb} / \mathrm{s}$ into the beginning of the next century. Using additional wavelengths to carry multiple $2.5 \mathrm{~Gb} / \mathrm{s}$ or $10 \mathrm{~Gb} / \mathrm{s}$ channel on a single fiber-wavelength division multiplexing-provides the needed capacity.

Bellcore, AT\&T and others have demonstrated the ability to scnd approximately 20 independent data channels on a single fiber. Transporting on the order of one hundred 2-10 Gb/s data channels appears feasible. These laboratory demonstrations are complemented by vendor announcements of commercial products which will transport up to four $2.5 \mathrm{~Gb} / \mathrm{s}$ channels on a single fiber. Present communications company WDM installations can be characterized as isolated technology tests or two wavelength links to overcome particular infrastructure bottlenecks.

Even with the transport of many independent data channels-one per wavelength-losses in the fiber, multiplexers, de-multiplexers and connectors require the optical signal be regenerated every $30-50 \mathrm{~km}$. The availability of a pure light amplifier should eliminate the need for nearly all these electrical regenerators. If all of the wavelengths could be simultaneously amplified by one dcvice, it will be simpler and more economical than the corresponding electrical regenerator. Erbium Doped Fiber Amplifiers (EDFAs), which are now being fielded, have many of the characteristics of an ideal light amplifier and can simultancously amplify many independent wavelengths. While not totally ideal devices, EDFAs can bc a major tool in reconfiguring the infrastructure.

\section{2: Flexibility}

The introduction of Erbium Doped Fiber Amplifiers (EDFAs) and optical switches has added the flexibility to span greater distances and deploy large portions of the infrastructure without regard to signal data formats. While the vast majority of the traffic will use 
telecommunications industry digital data standards, non standard analog and digital signals can also be routed between sites. Further, these 'clear channel' links can be scheduled, thereby giving network providers greater market flexibility.

The signal degradation caused by the infrastructurefibers, active and passive components-is such that regenerators must detect and clean up the signals within some maximum distance. That distance is related to the data rate, the quality and detailed characteristics of both the fiber infrastructure and the light sources. By optically modulating very pure, very narrowband laser light, 2.5 $\mathrm{Gb} / \mathrm{s}$ optical signals can be sent about $400 \mathrm{~km}$ between regenerators. By applying special compensating functions, that distance can be doubled or quadrupled. However, the number of different signals which can be carried in the same fiber will depend on how uniformly the optical amplifiers treat each wavelength.

Devices which can route individual wavelengths through a fiber nexus have been demonstrated. Each has delay, jitter, and loss characteristics which must be taken into account. The most significant impact, however, is that now each of the individual wavelengths on a fiber can have traveled different total path lengths between regenerators. Optical amplifiers and switching elements will be seeing different amplitude signals at different wavelengths.

Transporting and switching data in the optical domain is most exciting because the transport is format independent or transparent. However, the cost of enjoying this data format freedom will be in implementing the operation, administration, management and provisioning of a hetcrogeneous network. Most large networks currently deployed are homogenous and use standard telecommunications transport formats that have built-in capabilities to operate and manage the network. Those capabilities cannot easily be built into a format-free, transparent network. Fortunately, the majority of the traffic will use the standard digital formats suggesting it may be possible to utilize them to provide management of the non-standard signal paths.

In summary, traditional networking techniques that use today's technology and the current national infrastructure will not be good enough to implement the 'information superhighway.' New, all-optical networks which can increase the amount of information carried on each fiber in a network by one hundredfold will have the potential capacity and flexibility to serve these needs far into the future. It will be necessary to design and implement a succession of networks which include improvements in technology as they become available. The first experiments will involve point-to-point WDM connections to which longer links and switching will be added. Traditional architectures will be re-examined and the management of the transparent component of these networks addressed. At each stage the economics of making new traditional installations will be challenged by the economic advantage of increasing the capacity or flexibility of the currently installed infrastructure.

\section{3: High speed optical links at LLNL}

\section{1: Project OART (Optical Amplifier Reliability Trial)}

Pacific Bell, Lawrence Livermore National Laboratory (LLNL), and the University of California at Berkeley (UCB) have established a joint fiber testbed (Figure 1). This project will be a year long collaborative test involving the wavelength division multiplexing of data and video on a link using erbium doped fiber amplifiers. Project OART will provide Pacific Bell and Livermore with a valuable testbed for gathering information and experience with future network designs that will use WDM, EDFAs, and the simultaneous transmission of high-speed digital and video information. LLNL's interest in this link is further driven by a need to evaluate various future means of interconnecting high performance users with high performance storage and computation sites via long distance connections.

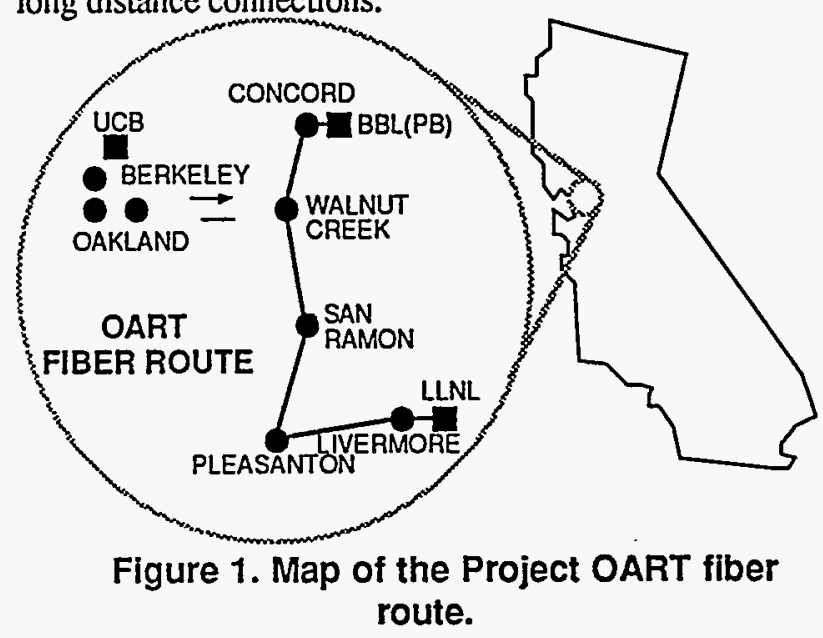

The fully implemented OART link will consist of a four channel WDM system on a pair of fibers over a link amplified by two pairs of EDFAs. The fiber used in the trial is representative of Pacific Bell's current fiber plant. The link has rather high loss and high reflections (high rcturn loss) due to many below average splices and older generation Biconic connectors in the fiber plant. Three wavelengths will be digital data communication channels transmitted between LLNL in Livermore and UCB in Berkeley at a distance of $98 \mathrm{~km}$. Pacific Bell has expressed intcrest in testing video transport from a test facility in 
Concord multiplexed over $73 \mathrm{~km}$ of the link to a video lab at LLNL. Presently two channels are operational-one carrying $266 \mathrm{Mb} / \mathrm{s}$ Fibre Channel traffic and a second carrying $622 \mathrm{MB} / \mathrm{s}$ XUNET Taxi traffic. UNIV OFCA

UNL

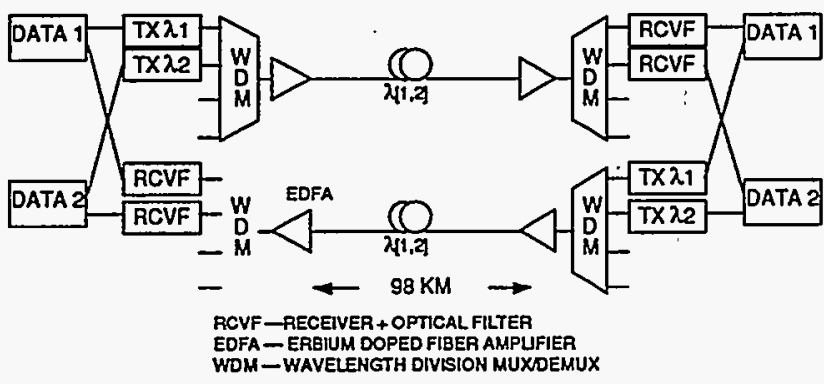

Figure 2. Diagram of present two channel configuration of Project OART.

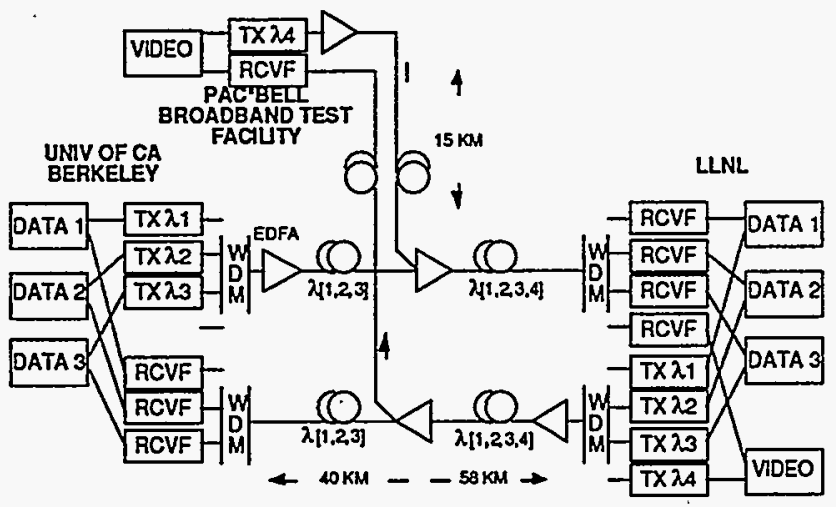

Figure 3. Diagram of proposed full implementation of Project OART.

A demonstration using clear channel long haul 266 $\mathrm{Mb} / \mathrm{s}$ Fibre Channel to interconnect two workstations using a high speed RAID disk array will be performed over the link in February, 1995. This will emulate the scenario of a local/remote high speed disk server. In a second test a second high speed RAID disk array will be installed at the other end of the link in order to demonstrate remote disk shadowing/mirroring.

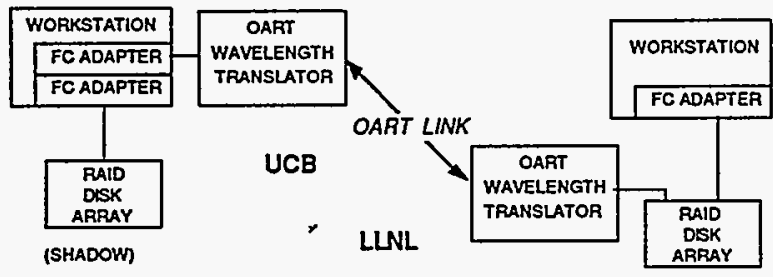

UNK TALKS FCP (SCSI OVER FC)

Figure 4. Remote shadowing high speed disk arrays.
The current trial is scheduled to end in June, 1995. Negotiations are in progress to extend this trial to evaluate other technology issues. Of particular interest is characterizing the ability to transmit multi-gigabit SONET traffic on this link.

The fiber optic components used in the OART link are shown on the detailed block diagram of the LLNL optical terminal (Figure 5). A wavelength translation (regenerator) chassis was designed (Figure 6) in order to provide a long haul, narrow linewidth $1550 \mathrm{~nm}$ laser transceiver interface that could interconnect with short haul Fibre Channel transceivers (typically $780-850 \mathrm{~nm}$ ) and XUNET intermediate transceivers $(1310 \mathrm{~nm})$. An optional clock resynchronization circuit is included in this chassis on the receiver.

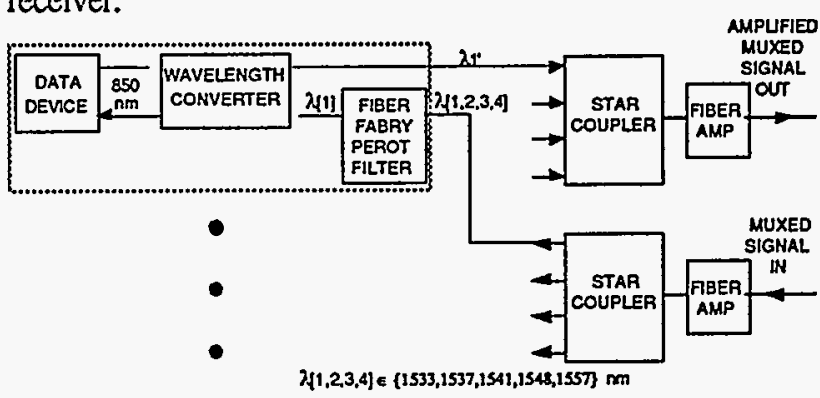

Figure 5. Detailed block diagram of the optical terminal.

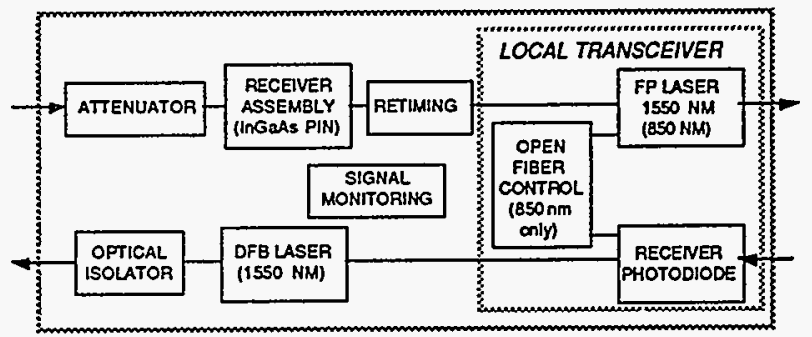

Figure 6. The optical wavelength

translator (regenerator) chassis.

Two EDFAs are used on each fiber connecting LLNL and UCB in order to provide a sufficient power budget margin to adequately study the relative power level difference effects on the high-speed data channels and the simultaneous transmission of AM-VSB video. This was primarily because of the much more stringent performance requirements of transmitting AM-VSB video over long distances. However, in addition we wanted to allow for higher than average (Biconic) connector losses, dispersion compensation expcriments and longer link tests.

We have developed interactive models of the power loss budgct which we have used for determining the optimum location of the fiber amplifiers in the system. We are planning to develop more comprehensive noise models for use in evaluating the link. We are also preparing a detailed characterization and analysis of the link return loss. 


\section{2: Scalable optical networks}

The Advanced Research Projects Agency (ARPA) and the Optical Network Technology Consortium (ONTC) are funding the development of optical switching technology to demonstrate the viability of scalable, modular 'All Optical Networks.' By routing individual wavelengths and providing a mechanism for wavelength re-use, it is possible to have isolated, same wavelength sub-nets on a common optical mesh. Without such isolation and re-use, the number of required wavelengths for a WDM network increases, at best, linearly with the number of end nodes. Sustaining the transparency is a function of the mechanism used to perform wavelength translation. The ONTC elected to perform the translation whenever performing electrical regeneration and ended up with the architecture shown in Figure 7.

The ONTC is led by Bellcore, and includes Columbia University, Hughes, LLNL, Northern Telecom, Rockwell and United Technologies Research, and United Technologies Photonics. The consortium has demonstrated a 4 wavelength network using AcoustoOptical Tunable Filters (AOTF's) to route $155 \mathrm{Mb} / \mathrm{s}$ ATM/SONET traffic between consortium-developed multi-wavelength transceivers. Sub-carrier multiplexing traffic is demonstrating the transparency of the network.

Current activities are geared toward increasing the bandwidth to $2.5 \mathrm{~Gb} / \mathrm{s}$ and the number of wavelengths to eight.

\section{3: A $10 \mathrm{~Gb} / \mathrm{s}$ ring around San Francisco Bay}

A similar consortium will be implementing a four wavelength optical network as an open testbed for emerging optical technologies, as well as a showcase for the applications enabled by the higher data rates. This too will be a project jointly funded by ARPA and consortium participants. Using Pacific Bell and Sprint fibers, the NTONC will field a $10+\mathrm{Gb} / \mathrm{s}$ WDM backbone network connecting nodes at LLNL, Pacific Bell, UC Berkeley and Sprint. Tributaries to pioneer application developers and to the San Jose and Moscone convention centers will provide additional access to the prototype network and technology testbed. Scheduled to begin in January of 1995, detailed design and application recruiting is just beginning. The first technology demonstration will be of the AOTF's and transceiver modules described above. Additional commercial components will be fielded to support the prototyping of applications independent of the evolving technology (Figure 8). The National Transparent Optical Network Consortium (NTONC) is led by

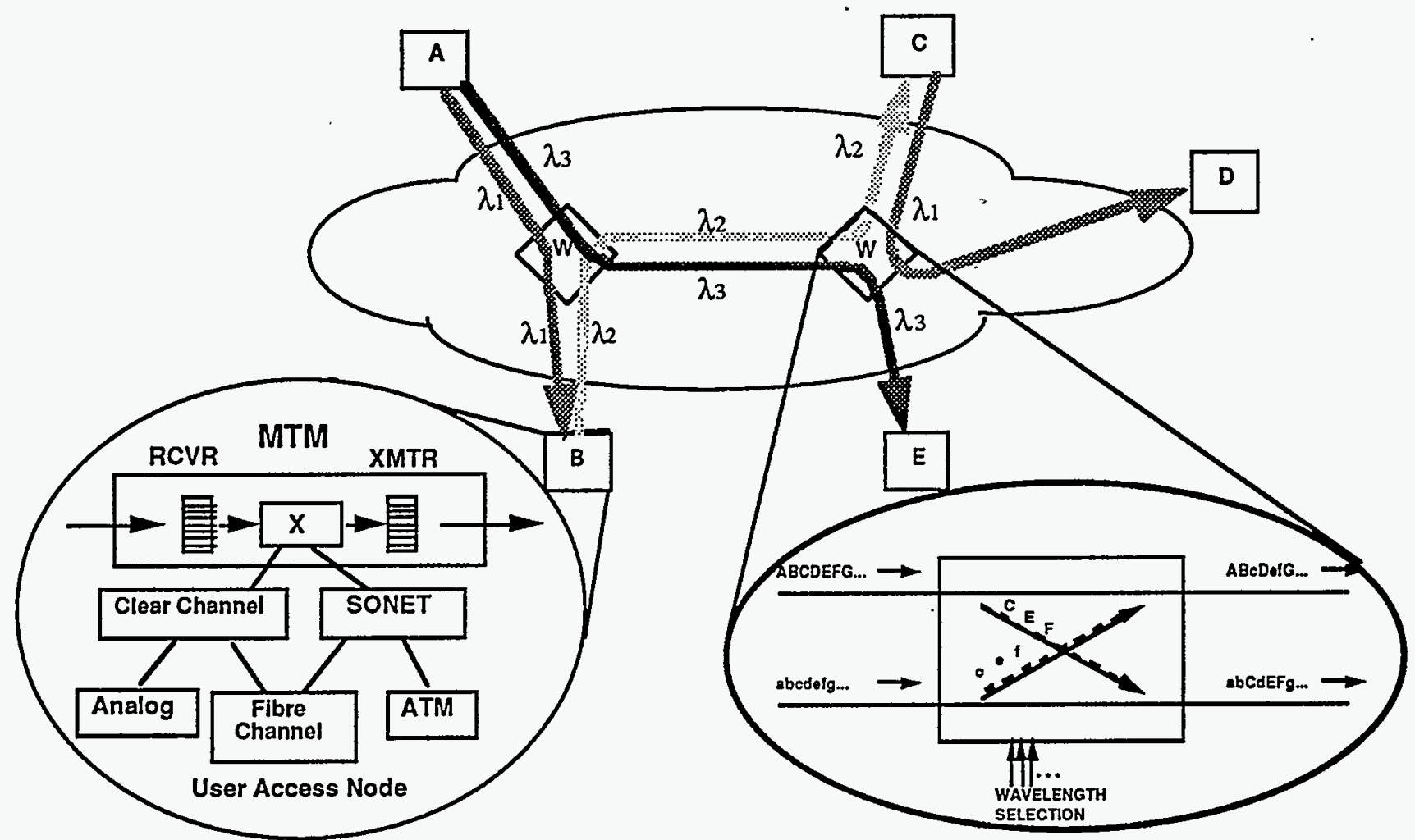

Figure 7. The ONTC is using wavelength routing and wavelength re-use to achieve a scalable, modular network. 
Northern Telecom, which is also the lead for developing and integrating the optical technology. LLNL is the network systems integrator and architect. The consortium members are Case Western Reserve University, Columbia University, Hughes, LLNL, Rockwell, Pacific Bell, Sprint, United Technologies Photonics and United Technologies Research Center.

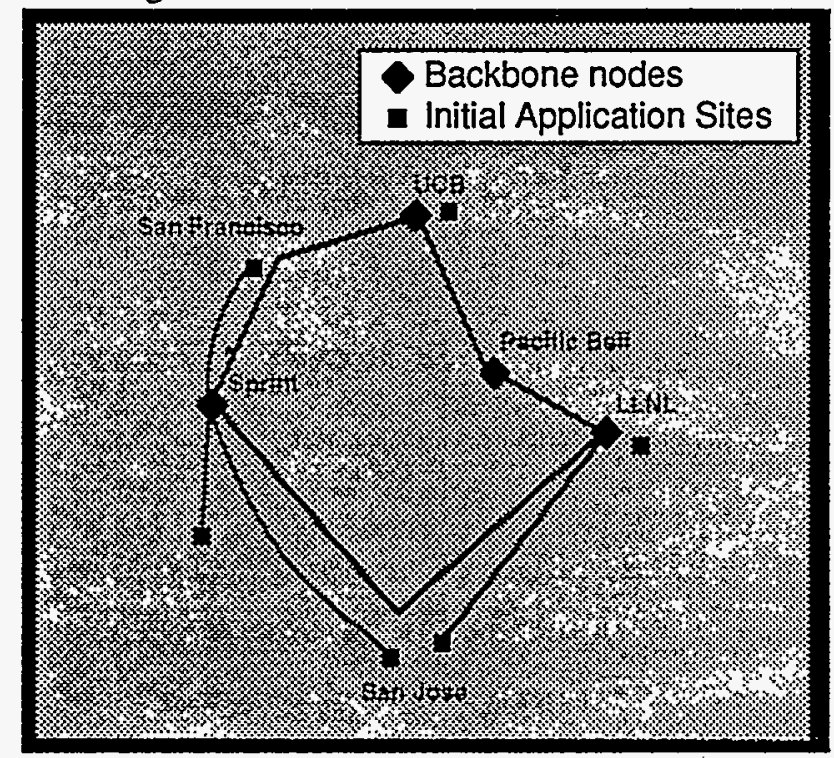

\section{Figure 8. NTONC prototype network and technology testbed.}

\section{4: Conclusion}

The Advanced Telecommunications Program at LLNL is complementing thrusts to drive on-site and off-site network technology by fostering optical technologies to reduce high speed network deployment costs. We are developing applications and testing components for wide area networking over high speed, multichannel optical links. Project OART is a multichannel, protocol independent, optical link that we will use to examine WAN transport and WDM issues. We have performed extensive tests of the link components in the lab and are now moving the link into the field. We are applying the results of these experiments in the deployment of a 10 $\mathrm{Gb} / \mathrm{s}$ optical ring around San Francisco Bay. These collaborations allow us to be in the forefront of optical networks and the application of wavelength division multiplexing to WAN infrastructure. These and the future collaborations enabled by the prototype networks and applications provide our partners with 'pre-competitive' opportunities to test technologies and evolve standards and to establish new, robust competitive markets.

\section{5: Acknowledgments}

We would like to thank Kent McCammon, Ron Haigh and Daren Sweider in the Photonics Group at LLNL and Dan Leslie and Pat Hart at Pacific Bell for their helpful discussions and technical support. Work performed under the auspices of the U. S. Department of Energy by Lawrence Livermore National Laboratory under Contract W-7405-Eng-48.

\section{Selected bibliography}

Acampora, Anthony S. "The Scalable Lightwave Network." IEEE Communications Magazine, Dec 1994 Vol. 32, No. 12. pp.36-43.

Bracketl, Charles A. , Anthony S. Acampora, Greg Tangonan, Mark Smith, William Lennon, K.C. Wang and Robert H. Hobbs, "A Scalable Multiwavelength Multihop Optical Network: A Proposal to DARPA for Research on All-Optical Networks," IEEE Journal of Lightwave Technology, pp.736753, May/June 1993, v 11, No. $5 / 6$.

Chidgey, Peter J. "Multi-Wavelength Optical Networks". IEEE Communications Magazine, Dec 1994 Vol. 32, No. 12. pp.28-35.

Gilder, George F. "Into the Fibersphere", Forbes ASAP, Dec 7, 1993. Archived at http://www.seas.upenn.edu/

Green, Paul Eliot, Fiber optic networks. Englewood Cliffs, NJ: Prentice Hall, 1993. ISBN: 0133194922

Green, Paul E. "Toward Customer Useable All-Optical Networks." IEEE Communications Magazine, Dec 1994 Vol. 32. No. 12. pp.44-49.

Kasovsky, Leonid, T. Fong and T. Hofmeister. "Optical Local Area Network Technologies." IEEE Communications Magazine, Dec 1994 Vol. 32, No. 12. pp. 50-55.

Spirit, Dave M., A.D. Ellis, and P. E. Barnsley. "Optical Time Division Multiplexing: Systems and Networks." IEEE Communications Magazine, Dec 1994 Vol. 32, No. 12. pp. 56-62. 


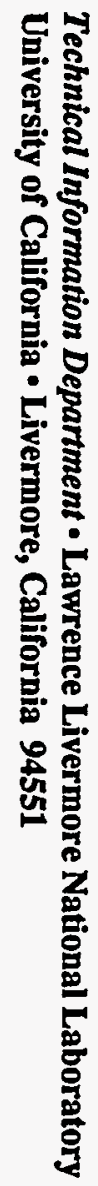

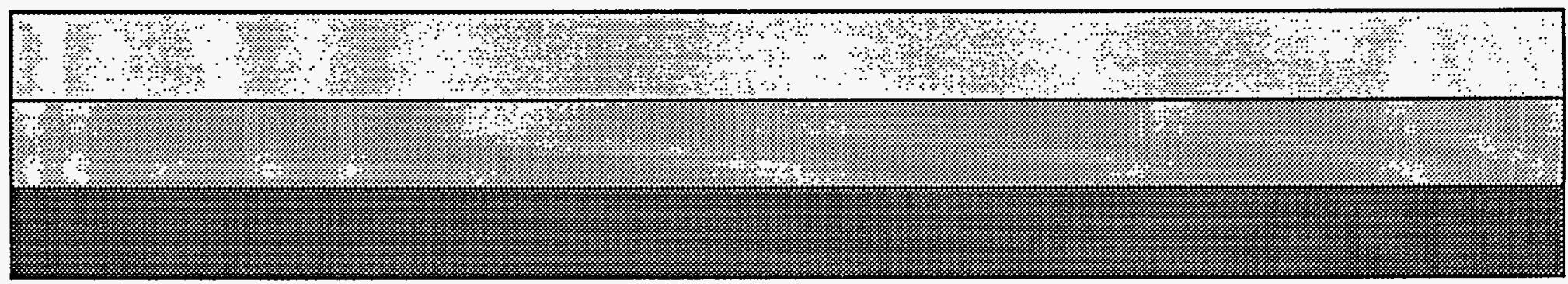

